\title{
Lobular Hemangioma
}

National Cancer Institute

\section{Source}

National Cancer Institute. Lobular Hemangioma. NCI Thesaurus. Code C3480.

A friable, benign vascular neoplasm with lobular capillary architecture that presents as a raised red skin growth. 